INTERNATIONAL JOURNAL OF SCIENTIFIC RESEARCH

ASSESSMENT OF KNOWLEDGE ON FIRST AID AND BASIC LIFE SUPPORT AMONG FINAL YEAR UNDERGRADUATES AND INTERNS OF A TERTIARY MEDICAL COLLEGE HOSPITAL, KANCHIPURAM

\title{
Community Medicine
}

\begin{tabular}{ll}
$\begin{array}{l}\text { Dr. Solomon } \\
\text { Rajkumar.P* }\end{array}$ & $\begin{array}{l}\text { Postgraduate student, Department of Community Medicine, MMCH\&RI, Kanchipuram. } \\
\text { *Corresponding Author }\end{array}$ \\
\hline Dr. Kokila Selvaraj & Professor \& HOD, Department of Community Medicine, MMCH\&RI, Kanchipuram. \\
\hline Dr. Vidhya.M & Postgraduate student, Department of Community Medicine, MMCH\&RI, Kanchipuram. \\
\hline $\begin{array}{l}\text { Dr. Arun } \\
\text { jayakumar }\end{array}$ & $\begin{array}{l}\text { Assistant professor, Department of Community Medicine, Sri Muthukumaran medical } \\
\text { college and Research institute, Chennai. }\end{array}$ \\
\hline
\end{tabular}

\section{ABSTRACT}

Introduction: Every person should be aware of the skill of basic life support resuscitation (BLS) and its knowledge is vital for medical and paramedical personnel. Structured training \& retraining is required for its efficient execution which is lacking in the current medical curriculum. Basic situation analysis regarding the student s knowledge regarding BLS is necessary to develop a effective training programme.

Materials and Methods: A Cross sectional study was conducted among 248 final year UG students ( $\mathrm{n}=142)$ and interns $(\mathrm{n}=106)$ of a Private medical college using a pre tested validated questionnaire. The questions were based on American Heart Association BLS Guidelines and basic first aid which consist of 20 questions. The correct responses were given 1 mark each and total was obtained for 20 marks. The knowledge of the study participants were then categorized into 4 groups $(0-5=$ poor ; 6-10=fair ; 11-15=good; 16-20=Excellent). The results were analysed using SPSS version-21.0.

Results: In this study $\mathbf{3 8 . 9 \%}(\mathbf{n}=\mathbf{9 6})$ showed excellent knowledge, $\mathbf{1 8 . 4 \%}(\mathbf{n}=\mathbf{4 6})$ showed fair knowledge on First aid/BLS, 22.5\% $(\mathbf{n}=\mathbf{5 6})$ showed good knowledge and rest $\mathbf{2 0 . 2 \%}[\mathbf{n}=\mathbf{5 0}]$ were poor. About $\mathbf{1 5 \%}(\mathbf{n}=\mathbf{3 7})$ of Interns and $\mathbf{1 3 \%}(\mathbf{n}=\mathbf{3 2})$ of final year students had excellent knowledge of First aid/BLS and the difference between them was statistically significant.(p=0.002).

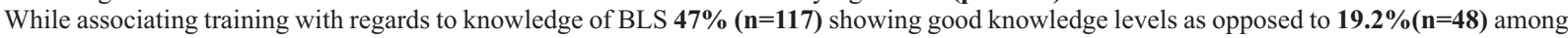
those who have not attended the training. $(\mathbf{p}=\mathbf{0 . 0 0 1})$. And associating training with regards to knowledge of first aid $\mathbf{6 6 . 5 \%}(\mathbf{n}=\mathbf{1 6 5})$ showing good knowledge levels as opposed to $\mathbf{3 2 . 3 \%}(\mathbf{n}=\mathbf{8 0})$ among who have not attended the training. $(\mathbf{p}=\mathbf{0 . 0 0 1})$

Conclusion: Knowledge of First aid and BLS was better among interns than final year undergraduates, with trained showing higher levels than the untrained.

\section{KEYWORDS}

basic life support, first aid, questionnaire, association and knowledge.

\section{INTRODUCTION:}

Life threatening emergencies can occur at anytime, anywhere and to anyone. Timely provision of First aid and Basic life support can save many precious lives ${ }^{[1]}$. It is important for everyone in the country to be aware of First aid and Basic life support, particularly health care professionals and trainees as they face life threatening situations frequently.

First aid is the immediate initial assistance or treatment given at the site of accident to the injured or ill before they receive the medical care. Basic life support (BLS) is a medical procedure or skill which saves the victim from the life threatening emergencies until medical support arrives [1].

Mouth to mouth and mouth to nose respiration have records from Egyptian mythology (Atum in Helippolitan myth) and the Holy Bible (Elijah in 1 Kings:17) which were the earliest resuscitative efforts using artificial respiration ${ }^{[2]}$. CPR is a simple but effective procedure invented in 1960 that allows anyone to sustain life in the early critical minutes after cardiac and respiratory arrest [2]

Data from India suggests that the awareness of first aid and BLS among students, doctors and the nurses of medical, dental and homeopathy is very poor [3]. In south India scarce data is present on knowledge of BLS and first aid hence this study.

Objective of the present study is to assess the level of knowledge on first aid and Basic life support among final year undergraduate medical students and interns and the association of training with level of knowledge among the selected study groups.

\section{METHODS}

Study design: It was a cross -sectional analytical study.

Study period: Six months (December 2018-May 2019)

Study setting: Meenakshi medical college and Hospital, Research Institute, Kanchipuram.

Sample size: Sample size consist 248.

Study population : Study subjects were the final year and intern
Medical Students of 2013-2018 batches of MMCH \& RI, Chennai. All students in the selected batches were included in the study.

Study tool: It is a semi-structured questionnaire.

\section{Study procedure:}

Ethical committee clearance was obtained from the Institutional Review Board of MMCH \& RI, Kanchipuram. Participants were separated into 2 groups [Intern and final year students]. The investigator explained the purpose and importance of the study to the participants and obtained consent for the study. Information was collected using a pre-tested validated questionnaire. The questionnaire was designed based on the available literature and consisted of two parts. The first part collected socio demographic information about the participant. The second part had twenty questions assessing the knowledge of BLS; each correct answer was scored 1 and each wrong answer was scored as 0 .

Those who obtained a total score of less than 5 were considered to have poor knowledge, 6-10 score were considered to have fair knowledge and those who got score equal or higher than score 15 were considered to have excellent knowledge. Questionnaires were completed anonymously, "in a class room" setting.

Every attempt was taken to avoid discussion among participants during the time of completing the questionnaire. The participants were motivated to fill the Performa completely. The participants who could not be contacted even after 3 attempts were excluded from the study.

\section{Data management and statistical analysis}

Data analysis was done using SPSS Version 21.0. Frequency \& median was calculated based on the type of variable. Standard Error, Interquartile range and $95 \%$ confidence interval was calculated. Association between variables was tested with Chi Square Test and where ever continuous variables were to be tested, Independent samples t test was used. The level of significance was taken at a $p$ value of $<0.05$ 
RESULTS:

The only demographic difference between the two groups was the proportion of males (Final years $52.3 \%$ vs Interns $31.8 \%, \mathrm{P}<0.01$ ). There was no difference in age in years (mean \pm SD; Interns $22.6 \pm 3.8$ vs Final years $20.9 \pm 2.1$ ). [Table: 1 ]

Majority of them were belonging to the age group 20- 24 years. Only 7 students were above the age of 23 and no one was below 20 years. In each year there were around 150 medical students and 100 intern students.

Table: 1 Sociodemographic analysis

\begin{tabular}{|l|l|l|l|}
\hline Course & Age & Gender \\
\hline
\end{tabular}

Table: 2 Knowledge of BLS among study population

\begin{tabular}{|l|l|l|l|l|l|}
\hline & & $\begin{array}{l}\mathbf{2 0 - 2 2} \\
{[166]}\end{array}$ & $\begin{array}{l}\mathbf{2 2 - 2 4} \\
{[\mathbf{8 2}]}\end{array}$ & $\begin{array}{l}\text { Male } \\
{[\mathbf{n}=102]}\end{array}$ & $\begin{array}{l}\text { Female } \\
{[\mathbf{n}=\mathbf{1 4 6}]}\end{array}$ \\
\hline \multirow{3}{*}{ Final years } & Number & $\mathbf{1 0 8}$ & $\mathbf{2 2}$ & $\mathbf{6 6}$ & $\mathbf{1 0 0}$ \\
\cline { 2 - 6 } & Percentage & $\mathbf{6 5 \%}$ & $\mathbf{2 7 \%}$ & $\mathbf{6 5 \%}$ & $\mathbf{6 8 \%}$ \\
\hline \multirow{3}{*}{ Interns } & Number & $\mathbf{5 8}$ & $\mathbf{6 0}$ & $\mathbf{3 6}$ & $\mathbf{4 6}$ \\
\cline { 2 - 6 } & Percentage & $\mathbf{3 5 \%}$ & $\mathbf{7 3} \%$ & $\mathbf{3 5} \%$ & $\mathbf{3 2} \%$ \\
\hline
\end{tabular}

The knowledge of the students regarding the BLS and firstaid were assessed by 20 questions. The Table 2 shows the knowledge of final year and Intern students regarding the various aspects of BLS resuscitation.

Response

\begin{tabular}{|c|c|c|c|c|}
\hline \multicolumn{4}{|c|}{ Right answered } & \multirow{3}{*}{$\begin{array}{l}\mathrm{P} \\
\text { value }\end{array}$} \\
\hline \multicolumn{2}{|c|}{ First year students $[n=139]$} & \multicolumn{2}{|c|}{ Interns [n=109] } & \\
\hline Number & Percentage & Number & Percentage & \\
\hline 122 & $88 \%$ & 97 & $89 \%$ & 0.04 \\
\hline 46 & $33 \%$ & 44 & $40 \%$ & 0.002 \\
\hline 95 & $68 \%$ & 74 & $68 \%$ & 0.002 \\
\hline 32 & $23 \%$ & 69 & $63 \%$ & 0.04 \\
\hline 110 & $79 \%$ & 90 & $83 \%$ & 0.04 \\
\hline 23 & $17 \%$ & 46 & $42 \%$ & 0.04 \\
\hline 21 & $15 \%$ & 48 & $44 \%$ & 0.002 \\
\hline 108 & $78 \%$ & 93 & $85 \%$ & 0.002 \\
\hline 97 & $70 \%$ & 103 & $94 \%$ & 0.005 \\
\hline 5 & $4 \%$ & 10 & $9 \%$ & 0.005 \\
\hline 22 & $16 \%$ & 61 & $56 \%$ & 0.005 \\
\hline 18 & $13 \%$ & 34 & $31 \%$ & 0.04 \\
\hline 41 & $29 \%$ & 51 & $47 \%$ & 0.04 \\
\hline 26 & $19 \%$ & 69 & $63 \%$ & 0.002 \\
\hline 34 & $24 \%$ & 76 & $69 \%$ & 0.005 \\
\hline 65 & $47 \%$ & 43 & $39 \%$ & 0.005 \\
\hline 87 & $63 \%$ & 92 & $84 \%$ & 0.004 \\
\hline 99 & $71 \%$ & 106 & $97 \%$ & 0.005 \\
\hline 67 & $48 \%$ & 76 & $70 \%$ & 0.005 \\
\hline 56 & $40 \%$ & 87 & $80 \%$ & 0.003 \\
\hline
\end{tabular}

How should you open the airway of an unconscious patient?

You are a loan first aider and have an unconscious non-breathing adult, what should you do first?

Which is the correct ratio of chest compressions to rescue breaths for use in

CPR of an adult patient

Which of the following is the correct sequence for the chain of survival?

What is the cause of angina?

Which test should you use if you suspect that a patient had a stroke?

Which of the following can cause a stroke?

What should your first action be when treating an electrical burn?

Which medical condition will develop from severe blood loss?

What names are given to the three different depths of burns?

What steps would you take to control bleeding from nose bleed?

\begin{tabular}{|l|l|l}
\hline You just performed 5 cycles of CPR on an adult. You reassess for a pulse. If no & $\mathbf{1 8}$
\end{tabular}

pulse, what is your next action?

An infant becomes unresponsive and stops breathing, A strong pulse is still

present. How many rescue breaths a minute should be given until help arrives

or the infant starts breathing on its own?

How often should you recheck for a pulse when you are performing rescue

breaths on an unconscious patient with a pulse?

Which of these answers appropriately describes how to perform chest

compressions on adult?

What is the compression to breath ratio when performing CPR on an infant with 65

2 providers?

Which of these acions is inappropriate when treating a chocking adult?

Where should you palpate for a pulse on unconscious adult during CPR

How long should you check for a carotid pulse on adult?

When should an unconscious patient be placed in the recovery position?

$P$ value less than 0.005 are highly significant.

Out of the 20 questions which measured the knowledge on BLS algorithm no participant answered all the questions correctly and no single question yielded $100 \%$ correct response from all the participants.

More intern students gave the correct response to 16 questions as compared to the medical students of the same institution. In twelve out of these sixteen questions the proportion of students giving correct responses were significantly higher among intern students. Of the four questions where the correct responses were more among final year students the difference was statistically significant only in one question A combined knowledge score was calculated by combining the score of the 20 questions and divided the study population into two groups based on their final score. Those who obtained a total score of less than 5 were considered to have poor knowledge, 5-10 score were considered to have good knowledge and those who got score equal or higher than score 15 were considered to have excellent knowledge.

Among the final year students $51.1 \%$ [Figure: 1] had only poor knowledge, while among intern students it was only $24 \%$. Among the final year students $13.7 \%$ had good knowledge regarding BLS, and $27.4 \%$ of intern students had good knowledge. The average score of intern students was significantly higher as compared to final year students, $6.6 \pm 2.5$ vs $8.5 \pm 2.8$ ( Mann - whitney test, $p$ value -0.001 ). [table: 3 ]

Intern students had highest knowledge of BLS compared to final year batches. The difference in the knowledge between the 2 batches was statistically significant. This can be due to the reason that Dept. of Community Medicine is conducting a two hour session on BLS for the first year students during their Community Medicine posting.

The final year students have undergone more hours of clinical training as compared to others and hence are more likely to have received information regarding BLS. These findings indicate the need for a structured programme for BLS.

Table: 3 Distribution of knowledge level according to the year of study.

\begin{tabular}{|c|c|c|c|c|}
\hline & \multicolumn{2}{|c|}{ Final year students } & \multicolumn{2}{c|}{ Interns } \\
\cline { 2 - 5 } & $\begin{array}{c}\text { Number } \\
{[\mathbf{1 4 2}]}\end{array}$ & Percentage & $\begin{array}{c}\text { Numbe } \\
\text { r [106] }\end{array}$ & Percentage \\
\hline Poor knowledge & $\mathbf{7 3}$ & $\mathbf{5 1 . 1 \%}$ & $\mathbf{2 4}$ & $\mathbf{2 4 \%}$ \\
\hline Good knowledge & $\mathbf{1 9}$ & $\mathbf{1 3 . 7 \%}$ & $\mathbf{2 8}$ & $\mathbf{2 7 . 4 \%}$ \\
\hline Fair knowledge & $\mathbf{2 9}$ & $\mathbf{2 0 . 2 \%}$ & $\mathbf{3 6}$ & $\mathbf{3 5 . 6 \%}$ \\
\hline Excellent knowledge & $\mathbf{2 1}$ & $\mathbf{1 5 \%}$ & $\mathbf{1 4}$ & $\mathbf{1 3 \%}$ \\
\hline
\end{tabular}

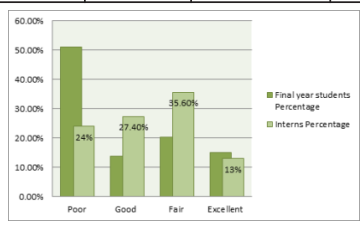

Figure: 1 Comparison of knowledge level according to the year of study 
Other reasons suggested by the students for poor knowledge were busy curriculum $(29.2 \%)$, lack of interest $(6.2 \%)$ etc. $242(97.5 \%)$ of study subjects were having the opinion that a structured programme on BLS resuscitation should be included in the curriculum. Only 6 students were suggested that there is no need to include the BLS in the curriculum.

\section{DISCUSSION:}

The present study revealed that the average knowledge score among the study participants was 7 with an interquartile range of 4 . The intern students were having significantly higher knowledge compared to medical students.

A study conducted by Sreedhara Avabratha et al revealed that only $13.3 \%$ of the interns had good knowledge regarding BLS and the average score was 9.05.[5] Raghava Sharma et al in their study reported that $19 \%$ of medical interns and $0 \%$ of dental interns had complete knowledge while $44 \%$ of medical interns and $88 \%$ of dental interns had poor knowledge regarding BLS.[6]

The study conducted by Chandrasekaran S et al reported that in their study $83 \%$ of medical students and $98.4 \%$ of nursing students scored less than $50 \%$ of marks and the practicing and teaching doctors scored less than the nursing teaching faculty.[7]

Study conducted by Sharma $\mathrm{R}$ et al reported that Resuscitation experience and training in BLS resulted in better knowledge score and thus boosted the confidence of study subjects. [6] In a study conducted by Zaheer $\mathrm{H}$ it was observed that only $14.9 \%$ of medical students attended BLS training during their course and these students had a significantly higher knowledge regarding BLS.[4]

Majority of the study participants reported that the major reason for the lack of knowledge among study participants is the lack of proper training in the curriculum. $97.5 \%$ of the study participants suggested that BLS should be included in the curriculum.

In the study conducted by Avabratha KS et al, all the study participants suggested to include BLS in the undergraduate curriculum.[5] Medical council of India is also recommending that Basic Life Support should be included in the undergraduate curriculum along with the foundation course itself.[8]

\section{CONCLUSION}

Knowledge regarding the BLS was less among the final year students of Meenakshi Medical College, Kanchipuram, India. Intern students were having higher knowledge than Medical students. But still when it comes to recommended level of knowledge, both groups need to improve. This may be achieved by repeated and yearly training sessions by introducing into the curriculum with assessment in UG period. It is mandatory that the people involved in medical field to know these life saving skills. Due to simplicity and effectiveness it is also important for every person in the community to get trained to save lives and improve the overall quality of community health.

\section{ACKNOWLEDGEMENTS}

Authors would like to express their sincere gratitude to MMCH\& RI, Kanchipuram. for giving all the support for the conduct of the project. Authors would also like to extend their heart felt gratitude to all the students who were willing to give their time for this project.

\section{Funding: NIL}

Conflict of interest: None declared

Ethical approval: The study was approved by the Institutional Ethics Committee, MMCH \&RI.

\section{REFERENCES}

1. Sasson C, Rogers MA, Dahl J, Kellermann AL. Predictors of survival from out-of hospital cardiac arrest: a systematic review and meta-analysis. Circ Cardiovasc Qual Outcomes. 2010;3(1):63-81.

2. American Heart Association- BLS for Health care Providers-Students manual. Part one,p-3 accessed on $12 / 12 / 2013$.

3. Skinner D, Camm A, Miles S. Cardiopulmonary skills of pre-registration house officers. BMJ. 1991; 302(6777):626-7

4. Zaheer H, Haque Z. Awareness about BLS (CPR) among medical students: status and requirements. J Pakistan Medical Association. 2009;59(1):57-9.

5. Avabratha KS, Bhagyalakshmi, Puranik G, Shenoy KV, Rai BS. A Study of the Knowledge of Resuscitation among Interns. Original Article. Al Ameen J Med Sci. 2012;5(2):152-6

6. Sharma R, Attar NR. Adult Basic Life Support (BLS) Awareness And Knowledge Among Medical And Dental Interns Completing Internship From Deemed University. Original Article. Nitte University Journal of Health Science. 2012;2(3).
7. Chandrasekharan S, Kumar S, Bhat SA, Kumar S, Shabbir PM, Chandrasekharan VP. Awareness of basic life support among medical, dental, nursing students and doctors. Indian J Anaesthesia. 2010;54(2):121-6.

8. Regulations on graduate medical education 2019 published by Medical council of India - part 9; page 21 